Gynäkologe 2020 · 53:683-688

https://doi.org/10.1007/s00129-020-04655-7

Published online: 15 September 2020

(C) The Author(s) 2020

\section{Redaktion}

L. Kiesel, Münster

W. Janni, Ulm

\begin{abstract}
Adenomyosis can cause dysmenorrhea, dyspareunia, bleeding disorders and pelvic pain and has a negative impact on fertility. The benign uterine disease can be found in almost $50 \%$ of patients with deep endometriosis, but also can appear without additional endometriosis. Adenomyosis is still underestimated and underdiagnosed and an exact incidence, especially related to patient age, is still not known. This might be related to the difficulties in diagnosing adenomyosis, although the diagnostic tools have a high accuracy in the hands of the skilled examiner. Considering adenomyosis allows the individualization of medicinal and surgical treatment in symptomatic and/or infertile patients.
\end{abstract}

The uterus is the central organ of the female pelvis and plays an indispensable role in reproduction. Adenomyosis is a benign disease of this important organ and knowledge about the impact of adenomyosis on symptomatology and fertility and its relation to additional peritoneal or deep endometriosis has been increasing over the years. Although the exact incidence of adenomyosis remains unclear, the disease seems to affect women from adolescence to menopause. Many patients with adenomyosis are symptomatic and report dysmenorrhea, dyspareunia, central pelvic pain and bleeding disorders. The negative impact of adenomyosis on fertility is still under discussion but several publications have shown reduced pregnancy and birth rates and higher abortion rates in

\author{
Harald Krentel ${ }^{1}$ Rudy Leon De Wilde ${ }^{2}$ \\ 'Clinic of Gynecology, Obstetrics, Gynecological Oncology and Senology, Bethesda Hospital Duisburg, \\ Academic Teaching Hospital, Duisburg, Germany \\ ${ }^{2}$ Clinic of Gynecology, Obstetrics and Gynecological Oncology, University Hospital for Gynecology, Pius- \\ Hospital Oldenburg, Medical Campus University of Oldenburg, Oldenburg, Germany
}

\title{
Adenomyosis: diagnostics and treatment
}

patients with adenomyosis undergoing reproductive treatment [1]. A risk for obstetric complications in patients with adenomyosis has recently been reported regarding premature birth, premature rupture of membranes, uterine rupture, postpartum hemorrhage, placentation failure and intrauterine fetal growth reduction [2]. It has been reported in various publications that medicinal and surgical treatment of adenomyosis may improve fertility [3] and reduces symptoms, although a standard for the treatment of infertile women with adenomyosis has not yet been established [4]. Hence it is of importance to consider adenomyosis as a possible factor in the diagnosis and treatment of all patients with endometriosis, corresponding symptoms or infertility. The identification of patients with adenomyosis allows individualized treatment approaches in relation to family planning status.

\section{From anamnesis to transvaginal ultrasound-The diagnosis}

As always, the clinical diagnosis starts with a detailed anamnesis. The clinical symptoms can lead to the suspicion of adenomyosis as most of the patients have typical symptoms, such as dysmenorrhea, bleeding disorders, chronic pelvic pain and dyspareunia. Adenomyosis might also be the reason for persistent symptoms after surgical interventions for peritoneal and deep endometriosis [5]. The gynecological examination may reveal a dolorous enlarged uterus and an additional palpable deep endometriosis of the retrocervical area
[6]. Almost 50\% of patients with deep endometriosis also have an involvement of the uterus. The most important diagnostic tool in the daily gynecological practice is the transvaginal ultrasound [7]. Several typical ultrasound signs have been described in the literature: myometrial cysts, subendometrial microcysts, question mark sign, heterogeneous myometrium, uterine asymmetry, hyperechoic myometrial lesions, subendometrial thickening, disruption of the junctional zone, subendometrial linear striae and uterine enlargement (• Fig. 1).

\section{》) The most important \\ diagnostic tool in daily \\ gynecological practice is \\ transvaginal ultrasound}

Although the meaning of the particular signs is not yet clear and a score system does not yet exist, the overall accuracy of 2D transvaginal ultrasound in the diagnosis of adenomyosis is high with a pooled sensitivity of $83.8 \%$ and a pooled specificity of $63.9 \%$ [8]. The 10 year meta-analysis [8] described the feature heterogeneous myometrium as the sign with the highest pooled sensitivity, while globular uterine enlargement was the most specific sign. The combination with the feature question mark sign increased the accuracy. A similar review showed comparable results pointing out the high heterogeneity between the included studies and the missing consensus in adenomyosis classification [9]. Different publications showed a high variation 


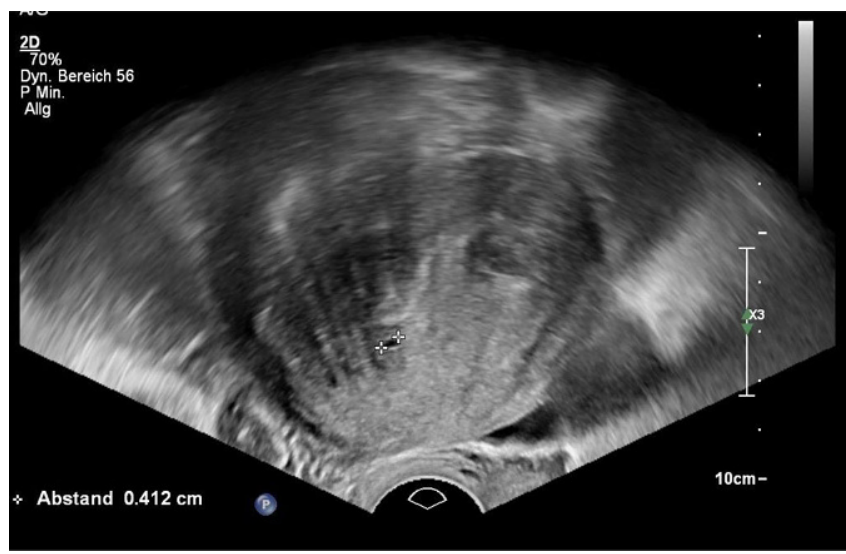

Fig. $1 \Delta$ Transvaginal ultrasound image of the uterus showing a subendometrial microcyst in adenomyosis (size $4 \mathrm{~mm}$ ) with associated linear striae. (With permission $\odot \mathrm{H}$. Krentel, all rights reserved)

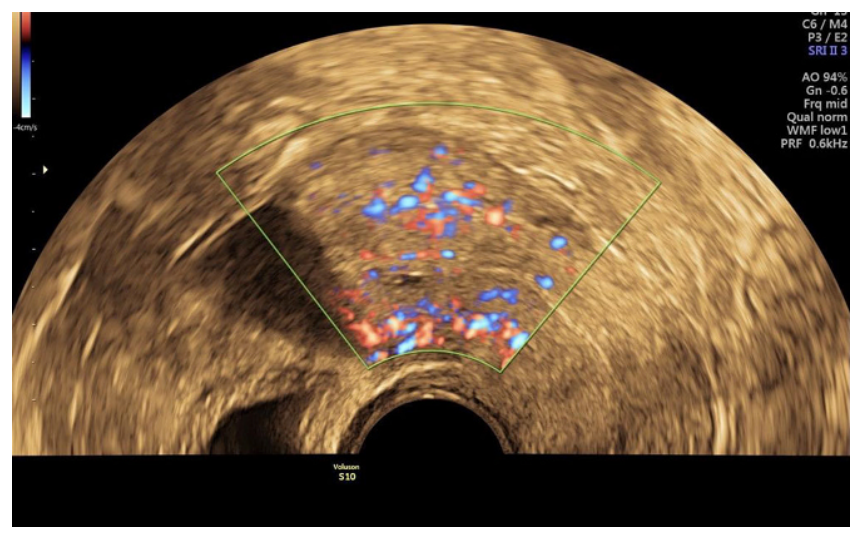

Fig. $2 \Delta$ Transvaginal ultrasound image of the uterus showing a subendometrial microcyst in adenomyosis. The additional colored doppler sonography helps to distinguish blood vessels (blue and red color) from microcysts with no color signal. (With permission $\odot \mathrm{H}$. Krentel, all rights reserved)

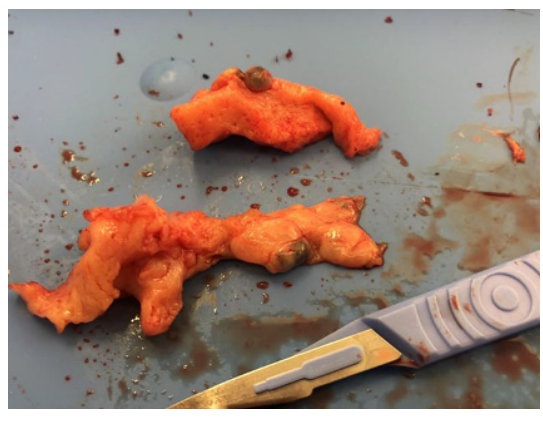

Fig. $3 \Delta$ Native tissue sample after hysterectomy showing myometrial tissue with subendometrial layer including microcysts in adenomyosis ( $3 \mathrm{~mm}$ ). (With permission @ H. Krentel, all rights reserved)

in the most useful ultrasound features, varying between linear striation, myometrial cysts, question mark sign, heterogeneous myometrium and asymmetrical myometrial thickening. Additional sonographic techniques can help to confirm the diagnosis of adenomyosis. In the examination of the junctional zone and its typical irregularities in adenomyosis, the $3 \mathrm{D}$ transvaginal ultrasound seems to be superior to $2 \mathrm{D}$ sonography. Doppler sonography can be used to distinguish adenomyosis (central flow) from fibroids (circular flow) by its typical flow characteristics and to differentiate small myometrial blood vessels from microcysts ([10]; - Fig. 2 and 3 ).

In combination with the clinical history and gynecological examination, transvaginal ultrasound is a potent diagnostic tool in the hands of the experienced examiner. The consensus statement of the morphological uterus sonographic assessment (MUSA) group on sonographic uterine features and the use of terminology summarized the actual status quo [11]. Specialized training and a standard ultrasound examination in all patients with typical symptoms may help to detect adenomyosis.

) Magnetic resonance imaging is a potential diagnostic tool with high accuracy

In order to detect focal and diffuse adenomyosis and to presurgically localize and measure the affected uterine tissue, magnetic resonance (MR) imaging is a potential diagnostic tool with high accuracy. The most important diagnostic sign in MR imaging seems to be the irregularity of the junctional zone (JZ), followed by focal or diffuse thickening of the JZ, a JZ(max) to myometrial thickness ratio $>40 \%$, areas of myometrial low signal intensity and high signal intensity spots in the T2-weighted technique are the typical findings [12, 13]. Bazot et al. compared transvaginal ultrasound with MR imaging and reported no difference in accuracy. In patients with additional uterine myomas the sensitivity was higher in MR imaging [12].

Laparoscopic signs of adenomyosis can be uterine enlargement, a pillowy resistance of the uterine wall, the blue sign and cystic subserous hemorrhagic lesions 
(• Fig. 5). Laparoscopy-guided myometrial biopsy techniques have been described as an accurate tool for obtaining a definitive diagnosis in patients with a clinical suspicion of adenomyosis [16].

The histologic proof can be helpful in therapeutic decisions, especially in cases of adenomyosis-related infertility. The accuracy of percutaneous, transvaginal, hysteroscopic and laparoscopic sampling techniques varies in relation to examiner experience and quality of ultrasound detection [17]. All diagnostic findings in adenomyosis can change in relation to patient age, hormonal treatment and menstrual cycle. In conclusion the diagnosis or exclusion of adenomyosis by the experienced gynecologist is possible. The individual combination of different diagnostic tools including imaging techniques and minimally invasive surgical approaches provide a high accuracy in the diagnosis of adenomyosis and in some cases even histological certainty.

\section{Surgical treatment when family planning is completed}

Adenomyosis can be treated by medicinal and/or surgical approaches including reproductive techniques. The decision on how to treat adenomyosis individually depends on the following factors: type of symptoms, family planning status, additional peritoneal and/or deep endometriosis and age. In patients with completed family planning adenomyosis can be definitively treated by laparoscopic total hysterectomy or laparoscopic subtotal hysterectomy when the uterine cervix is free of adenomyosis or retrocervical deep endometriosis. The laparoscopic approach allows the inspection of the complete pelvis and thus the simultaneous resection of additional endometriosis. In cases of subtotal hysterectomy, laparoscopic in bag morcellation of the uterine corpus should be performed in order to avoid iatrogenic new onset intraperitoneal or retroperitoneal adenomyosis, endometriosis, metastatic myomatosis, sarcoma or late onset malignant transformation of uterine tissue. Abdominal, laparoscopic or hysteroscopic adenomyomectomy in focal or cystic adenomyosis

Gynäkologe 2020 ·53:683-688 https://doi.org/10.1007/s00129-020-04655-7

(c) The Author(s) 2020

\section{H. Krentel · R. L. De Wilde}

\section{Adenomyosis: diagnostics and treatment}

Abstract

Background. Adenomyosis is a frequent additional condition in patients with endometriosis and should be included in diagnostic and treatment concepts.

Objective. Description of diagnostic and therapeutic approaches in patients with adenomyosis in relation to patient age, family planning status, peritoneal and/or deep endometriosis and symptoms.

Methods. The current literature on adenomyosis including case reports was analyzed. Due to the lack of evidenced-based approaches the most probable trends in diagnostics and treatment are discussed. Results. Adenomyosis plays an important role in fertile patients with dysmenorrhea, dyspareunia and pelvic pain, with or without additional peritoneal or deep endometriosis.
It has a negative impact on fertility and can cause a variety of symptoms. The disease can be diagnosed by a skilled examiner and treatment concepts exist.

Conclusion. Adenomyosis can be diagnosed by a combination of clinical history, gynecological examination, transvaginal ultrasound and magnetic resonance imaging. Various medical and surgical treatment approaches are available to reduce symptoms and to increase fertility. The course of action depends on the family planning status of the patient.

\section{Keywords}

Endometriosis · Infertility · Dyspareunia · Dysmenorrhea - Transvaginal ultrasound

\section{Adenomyose: Diagnostik und Therapie}

\section{Zusammenfassung}

Hintergrund. Die Adenomyose ist eine häufig auftretende Begleiterkrankung bei Patientinnen mit Endometriose und sollte in Diagnostik und therapeutischen Behandlungskonzepte mit einbezogen werden.

Ziel. Beschreibung der diagnostischen und therapeutischen Ansätze bei Patienten mit Adenomyose in Bezug auf Alter, Familienplanungsstatus, Peritoneal- und/oder tiefe Endometriose und Symptome.

Methoden. Die aktuelle Literatur zur Adenomyose einschließlich der Fallberichte wurde analysiert. Aufgrund mangelnder evidenzbasierter Ansätze werden die wichtigsten Entwicklungen in Diagnostik und Therapie diskutiert.

Ergebnisse. Die Adenomyose spielt eine bedeutende Rolle bei fruchtbaren Patientinnen mit Dysmenorrhö, Dyspareunie und Beckenschmerzen, mit oder ohne zusätzliche Peritoneal- oder tiefe Endometriose. Sie wirkt sich negativ auf die Fruchtbarkeit aus und kann eine Vielzahl von Symptomen verursachen. Die Erkrankung kann von einem qualifizierten Untersucher diagnostiziert werden. Für die Therapie stehen diverse Behandlungskonzepte zur Verfügung. Schlussfolgerung. Die Adenomyose kann durch eine Kombination aus klinischer Anamnese, gynäkologischer Untersuchung, transvaginalem Ultraschall und Magnetresonanztomographie (MRT) diagnostiziert werden. Zur Linderung der Symptome und zur Erhöhung der Fruchtbarkeit stehen verschiedene medizinische und chirurgische Behandlungsansätze zur Verfügung. Das weitere Vorgehen richtet sich nach dem Familienplanungsstatus der Patientin.

Schlüsselwörter

Endometriose · Infertilität · Dyspareunie . Dysmenorrhö · Transvaginaler Ultraschall and cytoreductive surgical procedures in diffuse adenomyosis can reduce symptoms in patients who wish to preserve the uterus. Focal subendometrial or intramural cystic adenomyotic lesions and intracavitary polypoid adenomyoma can be treated by hysteroresectoscopy. New instruments with a smaller diameter also provide a minimally invasive approach in very young nulliparous women. The hysteroscopic resection of adenomyotic lesions improves symptoms. Larger intramural cystic lesions should be treated by laparoscopic resection and uterine suturing (• Fig. 6; [18]). The influence of these procedures on patient fertility should by further investigated. 


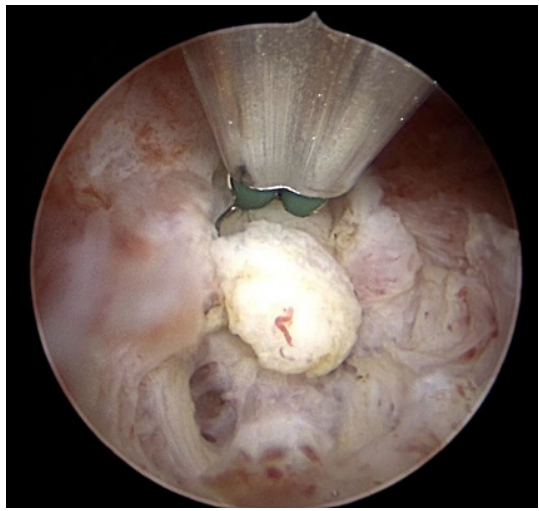

Fig. $4 \Delta$ Bipolar mini-hysteroresectoscopic biopsy technique. (With permission $\odot \mathrm{H}$. Krentel, all rights reserved)

Endometrial ablation offers a less invasive treatment option in patients who want to preserve the uterus; however, the efficacy in controlling bleeding decreases over time [19].

\section{Medical treatment options}

Another treatment option is the use of a levonorgestrel intrauterine device (LNG-IUD), gestagens or combined oral contraceptives. In the subgroup of patients with ongoing family planning the medical treatment can only be an option as a pretreatment before reproductive procedures or as a prophylactic treatment in very young women with adenomyosis and a pregnancy wish in the future. In these cases a long-term treatment with low complication rates and the aim to prevent a worsening of the uterine situation is required. All medical therapeutic possibilities in patients with adenomyosis have been recently reviewed by various authors [20, 21]. The suppressive hormonal treatments with high dose progestins, oral contraceptives, LNG-IUDs, gonadotropinreleasing hormone (GnRH) agonists, aromatase inhibitors, selective estrogen receptor modulator (SERM) and selective progesterone receptor modulator (SPRM) are able to reduce symptoms by reduction of adenomyosis; however, each of these treatments is related to specific side effects. Currently, all medical approaches represent an off-label use as no medical solution is licensed in the specific treatment of adenomyosis.
Dienogest is able to reduce adenomyosisrelated pelvic pain and dysmenorrhea but is combined with a high risk of irregular uterine bleeding as the most common adverse reaction. Therefore, patients treated with dienogest have a certain risk of treatment discontinuation especially when they are of young age, have anemia before treatment and/or have mildly supressed or unsuppressed estradiol after starting dienogest treatment [22]. Also, progestins such as norethisterone acetate or medroxyprogesteron acetate can reduce pain in patients with adenomyosis but are related to side effects, such as acne, edema and reduction of libido causing high discontinuation rates. Combined oral contraceptives represent another evidence-based therapeutic option. The data show a pain reduction but also bleeding disorders as the main adverse effect. The LNGIUD seems to be the most effective option in reducing pain and menstrual blood loss [23]. The LNG-IUDs can be used in women with completed family planning instead of hysterectomy, and as a maintenance therapy after adenomyosis surgery. In a retrospective analysis of treatment with LNG-IUD in patients with a large uterine adenomyosis and heavy menstrual bleeding, $10 \%$ underwent premature LNG-IUD removal and $16.7 \%$ underwent subsequent hysterectomy [24]. The incidence of spontaneous expulsion of the IUD is higher in patients with adenomyosis and/or uterine fibroids than in women with a normal uterus and seems to depend on the insertion technique and the placement timing. The role of LNG-releasing intrauterine systems in the treatment of adolescent or very young women with adenomyosis, especially the use of lowdose IUDs should be investigated. The use of LNG-IUDs prior to assisted reproduction also has been described but has not yet been scientifically evaluated. Another medical treatment option is the use of GnRH agonists or antagonists. The application can be presurgical, postsurgical, prior to assisted reproductive techniques or as an individual approach instead of other medical treatments. The presurgical treatment can reduce complications and bleeding in adenomyosis surgery. The combination of GnRH agonist application with conservative surgery seems to result in longer symptom control and better reproductive outcomes in symptomatic and subfertile patients with adenomyosis compared with $\mathrm{GnRH}$ treatment alone. In infertile women with adenomyosis the treatment with GnRH agonists is indicated before fertility treatment in order to increase pregnancy and birth rates and decrease abortion rates [25]. The efficacy of GnRH agonists in adolescents with refractory chronic pelvic pain, failed therapy with combined oral contraceptives and positive MR imaging for adenomyosis has been reported. The treatment improved symptoms and repeated MR imaging showed regression of the lesions [26]. As estrogen, estrogen receptors and aromatase play a role in the pathogenesis of adenomyosis, the therapeutic use of aromatase inhibitors is an additional option. The reduction of adenomyosis volume and symptoms has been shown; however only a few publications exist and further investigations are needed. Selective progesterone receptor modulators, selective estrogen receptor modulators, valproic acid and antiplatelet treatment represent another group of treatment options, which needs to be investigated before used in the daily routine. So far, the medical treatment of adenomyosis especially in patients with ongoing family planning is an individual recommendation, while the situation in patients with completed family planning is based on a large number of publications, especially regarding the use of LNG-IUDs.

\section{Surgical or combined treatment options in patients with ongoing family planning}

Patients with adenomyosis and infertility have various treatment options; however none of these options is evidence based. One way could be the direct reproductive approach with or without medical pretreatment. Another way could be the combination with uterus-sparing surgery, such as adenomyectomy or cytoreduction. The questions are if surgery has an additional benefit for infertile pa- 


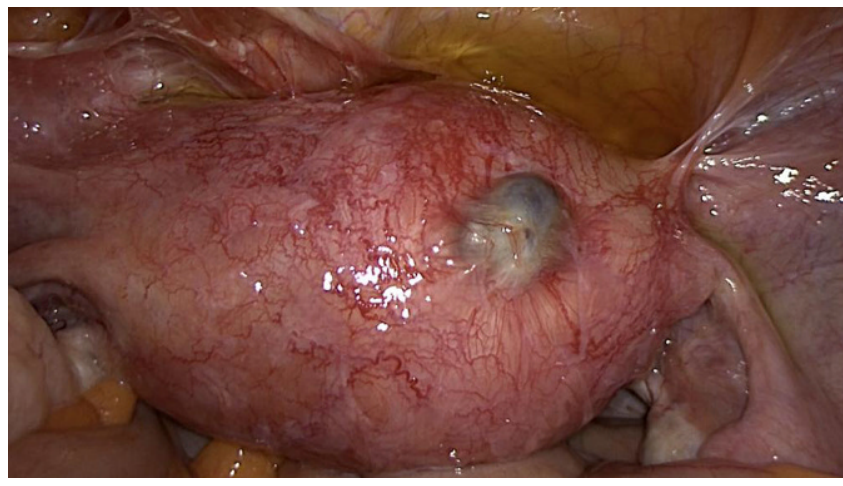

Fig. 5 - Laparoscopic view of subserous cystic adenomyosis. (With permission, $\odot \mathrm{H}$. Krentel, all rights reserved)

tients with adenomyosis and what would be the right moment for surgery? In a recent literature review these options including medical and surgical methods, highlighting treatment strategies, but also the lack of knowledge and the difficulties in suggesting evidence-based treatments, has been discussed [27]. An important factor in the patient selection for surgery is the patients age, which should be less than 39 years [28]. Additional surgery might be an option in symptomatic patients, who are not able to undergo reproductive procedures, patients with infertility despite in vitro fertilization and intracytoplasmic sperm injection (IVF/ ICSI) and as a last resort in extreme cases of diffuse adenomyosis. Surgery might be helpful in matters of fertility but the effect of surgery needs to be proven in the future [3].

\section{》) Important in patient selection for surgery is that patients should be less than 39 years old}

In a recent review an overall clinical pregnancy rate of $18.2 \%$ after surgical treatment of adenomyosis was described. The additional postoperative treatment with $\mathrm{GnRH}$ agonists increased the rate up to $40 \%$ [29]. The risks of surgical procedures in adenomyosis should not be underestimated. The surgery can be difficult and the loss of organs due to severe intraoperative bleeding has been described. Adenomyosis surgery can cause uterine

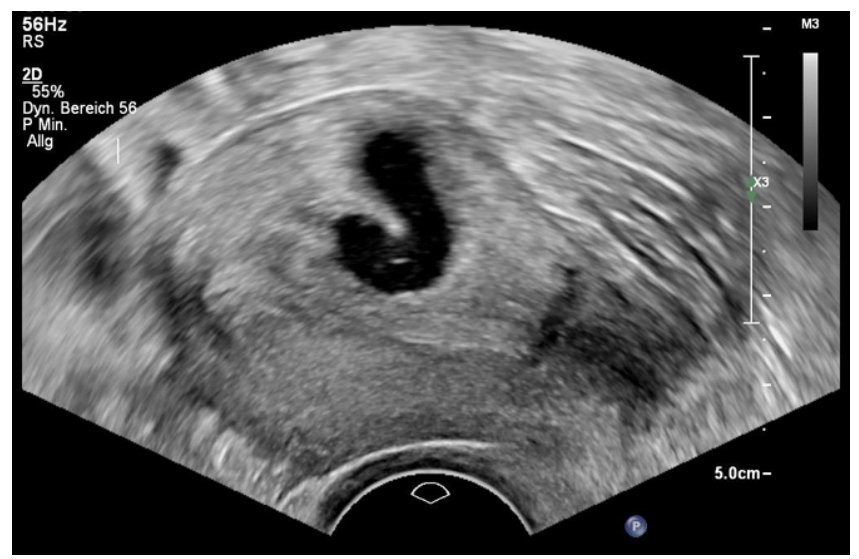

Fig. $6 \Delta$ Transvaginal ultrasound image of an intramural cystic adenomyosis in patient with ongoing family planning. (With permission $\odot \mathrm{H}$. Krentel, all rights reserved) rupture, postsurgical intrauterine and intra-abdominal adhesions and irregular placentation. In order to minimize complications adenomyosis surgery should be carried out in specialized centers with experienced gynecological surgeons.

\section{New minimally invasive treatment options}

High-intensity focused ultrasound (HIFU) and radiofrequency ablation are alternative treatment methods for focal and diffuse adenomyosis. Both techniques provide symptom relief and a low rate of major and minor complications in patients who wish to preserve the uterus or to conceive in the future. In recent publications patients undergoing HIFU for adenomyosis showed high conception and live birth rates after treatment [30]; however, the role of HIFU in patients who wish to conceive should be further investigated. The transcervical radiofrequency ablation for symptomatic adenomyosis has also been reported to be a safe and effective method. Also, uterine artery embolization can reduce symptoms and improve the quality of life in patients with symptomatic adenomyosis. The impact of uterine artery embolization on fertility and pregnancy requires further evaluation. The literature describes a wide range of therapeutic options, but none of them are evidence based and in relation to effectiveness, fertility outcome, reliability and side effects many questions still remain unanswered.
Prospective randomized trials are needed in order to show if medicinal, surgical or reproductive treatment alone or a combination is the best way to improve fertility in patients with adenomyosis. Patients with adenomyosis need an individual approach with detailed diagnosis of the extent of the disease and an accurate planning of the medicinal and/or surgical treatment.

\section{Recommendations for daily practice}

- Adenomyosis is a frequent benign uterine disease,

- Dysmenorrhea, dyspareunia, pelvic pain and bleeding disorders are typical symptoms,

- Adenomyosis has a negative impact on fertility,

- Adenomyosis can be diagnosed by a combination of clinical history, gynecological examination and transvaginal 2D ultrasound,

- MR imaging can be useful as an additional diagnostic tool,

- The treatment approach depends on the patient's family planning and the type and localization of the disease,

- Medicinal treatment and surgical resection of adenomyosis can reduce symptoms,

- Adenomyosis surgery should only be performed in specialized centers. 


\section{Corresponding address}

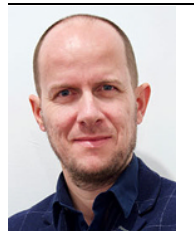

\section{Dr. Harald Krentel}

Clinic of Gynecology,

Obstetrics, Gynecological

Oncology and Senology,

Bethesda Hospital Duisburg,

Academic Teaching Hospital

Duisburg, Germany

h.krentel@bethesda.de

\section{Compliance with ethical guidelines}

Conflict of interest. H. Krentel and R.L. De Wilde declare that they have no competing interests.

Ethical standards. For this article no studies with human participants or animals were performed by any of the authors. All studies performed were in accordance with the ethical standards indicated in each case.

Open Access. This article is licensed under a Creative Commons Attribution 4.0 International License, which permits use, sharing, adaptation, distribution and reproduction in any medium or format, as long as you give appropriate credit to the original author(s) and the source, provide a link to the Creative Commons licence, and indicate if changes were made. The images or other third party material in this article are included in the article's Creative Commons licence, unless indicated otherwise in a credit line to the material. If material is not included in the article's Creative Commons licence and your intended use is not permitted by statutory regulation or exceeds the permitted use, you will need to obtain permission directly from the copyright holder. To view a copy of this licence, visit http://creativecommons.org/licenses/by/4.0/.

\section{References}

1. Younes G, Tulandi T (2017) Effects of adenomyosis on in vitro fertilization treatment outcomes: a meta-analysis. Fertil Steril 108(3):483-490

2. Buggio L, Monti E, Gattei U, Dridi D, Vercellini $P$ (2017) Adenomyosis: fertility and obstetric outcome. A comprehensive literature review. Minerva Ginecol. https://doi.org/10.23736/ S0026-4784.17.04163-6

3. Dueholm M (2017) Uterine adenomyosis and infertility, review of reproductive outcome after in vitro fertilization and surgery. Acta Obstet Gynecol Scand 96(6):715-726

4. Tamura H, Kishi H, Kitade M, Asai-Sato M, Tanaka A Murakami T, Minedishi T, Sugino N (2017) Clinical outcomes of infertility treatment for women with adenomyosis in Japan. Reprod Med Biol 16(3):276-282

5. Ferrero S, Camerini G, Menada MV, Biscaldi E, Ragni N, Remorgida V (2009) Uterine adenomyosis in persistence of dysmenorrhea after surgical excision of pelvic endometriosis and colorectal resection. JReprod Med 54(6):366-372

6. Krentel H, Cezar C, Becker S, Di Spiezio Sardo A, Tanos V, Wallwiener M, De Wilde RL (2017) From clinical symptoms to MRimaging: diagnostic steps in adenomyosis. Biomed Res Int 2017:1514029

7. Graziano A, Lo Monte G, Piva I, Caserta D, Karner M, Engl B, Marci R (2015) Diagnostic findings in adenomyosis: a pictorial review on the major concerns. Eur Rev Med Pharmacol Sci 19(7):1146-1154

8. Andres MP, Borelli GM, Ribeiro J, Baracat EC Abrao MS, Kho RM (2018) Transvaginal ultrasound for the diagnosis of adenomyosis: systematic review and meta-analysis. J Minim Invasive Gynecol 25(2):257-264

9. Bazot M, Darai E (2018) Role of transvaginal sonography and magnetic resonance imaging in the diagnosis of uterine adenomyosis. Fertil Steri 109(3):389-397

10. Benagiano G, Brosens I, Habiba M (2015) Adenomyosis: a life-cycle approach. Reprod Biomed Online 30(3):220-232

11. Van den Bosch T, Dueholm M, Leone FP, Valentin $L$ Rasmussen CK, Votino A, Van Schoubroeck D, Landolfo $C$, Installé AJ, Guerriero $S$, Exacoustos $C$ Gordts S, Benacerraf B, D'Hooghe T, De Moor B, Brölmann H, Goldstein S, Epstein E, Bourne T, Timmerman D (2015) Terms, definitions and measurements to describe sonographic features of myometrium and uterine masses: a consensus opinion from the Morphological Uterus Sonographic Assessment (MUSA) group. Ultrasound Obstet Gynecol 46(3):284-298

12. Bazot M, Cortez A, Darai E, Rouger J, Chopier J, Antoine JM, Uzan S (2001) Ultrasonography compared with magnetic resonance imaging for the diagnosis of adenomyosis: correlation with histopathology. Hum Reprod 16(11):2427-2433

13. Novellas S, Chassang M, Delotte J, Toullalan O, Chevallier A, Bouaziz J, Chevallier P (2011) MRI characteristics of the uterine junctional zone: from normal to the diagnosis of adenomyosis. AJR Am J Roentgenol 196(5):1206-1213

14. Di Spiezio Sardo A, Calagna G, Santangelo $F$ Zizolfi B, Tanos V, Perino A, De Wilde RL (2017) The role of hysteroscopyin the diagnosis and treatment of adenomyosis. Biomed Res Int 2017:2518396

15. Dakhly DM, Abdel Moety GA, Saber W, Gad Allah SH, Hashem AT, Abdel Salam LO (2016) The accuracy of hysteroscopic endomyometrial biopsy in diagnosis of adenomyosis. J Minim Invasive Gynecol 23(3):364-371

16. Jeng CJ, Huang SH, Shen J, Chou CS, Tzeng CR (2007) Laparoscopy-guided myometrial biopsy in the definite diagnosis of diffuse adenomyosis. Hum Reprod 22(7):2016-2019

17. Movilla P, Morris S, Isaacson K (2019) A systematic review of tissue sampling techniques for the diagnosis of adenomyosis. J Minim Invasive Gynecol. https://doi.org/10.1016/j.jmig.2019.09. 001

18. Gordts S, Campo R, Brosens I (2014) Hysteroscopic diagnosis and excision of myometrial cystic adenomyosis. Gynecol Surg 11(4):273-278

19. Philip CA, Le Mitouard M, Maillet L, de SaintHilaire P, Huissoud C, Cortet M, Dubernard G (2018) Evaluation of Novasure global endometrial ablation in symptomatic adenomyosis: a longitudina study with a 36 month follow-up. Eur J Obstet Gynecol Reprod Biol 227:46-51

20. Vannuccini $S$, Luisi $S$, Tosti $C$, Sorbi F, Petraglia F (2018) The role of medical therapy in the management of uterine adenomyosis. Fertil Steril 109(3):398-405

21. Pontis A, D'Alterio MN, Pirarba $S$, de Angelis $C$, Tinelli R, Angioni S (2016) Adenomyosis: a sys- tematic review of the medical treatment. Gynecol Endocrinol 32(9):696-700

22. Nagata C, Yanagida S, Okamoto A, Morikawa A Sugimoto K, Okamoto S, Ochiai K, Tanaka T (2012) Risk factors of treatment discontinuation due to uterine bleeding in adenomyosis patients treated with dienogest. J Obstet Gynaecol Res 38(4):639-644

23. Imai A, Matsunami K, Takagi H, Ichigo S (2014) Levonorgestrel-releasing intrauterine device used for dysmenorrhea: five-year literature review. Clin Exp Obstet Gynecol 41(5):495-498

24. Park DS, Kim ML, Song T, Yun BS, Kim MK, Jun HS, Seong SJ (2015) Clinical experiences of the levonorgestrel-releasing intrauterine system in patients with large symptomatic adenomyosis. Taiwan JObstet Gynecol 54(4):412-415

25. Streuli I, Dubuisson J, Santulli P, de Ziegler D, Batteux F, Chapron C (2014) An update on the pharmacological management of adenomyosis. Expert Opin Pharmacother 15(16):2347-2360

26. Mansouri R, Santos XM, Bercaw-Pratt JL, Dietrich JE (2015) Regression of adenomyosis on magnetic resonance imaging after a course of hormonal supression in adolescents: a case series. J Pediatr Adolesc Gynecol 28(6):437-440

27. Dueholm M (2018) Minimally invasive treatment of adenomyosis. Best Pract Res Clin Obstet Gynaecol. https://doi.org/10.1016/j.bpobgyn.2018.01.016

28. Kishi Y, Yabuta M, Taniguchi F (2014) Who will benefit from uterus-sparing surgery in adenomyosis-associated subfertility? Fertil Steril 102(3):802-807

29. Rocha TP, Andres MP, Borelli GM, Abrao MS (2018) Fertility-sparing treatment of adenomyosis in patients with infertility: a systematic review of current options. Reprod Sci 25(4):480-486

30. Zhang L, Rao F, Setzen R (2017) High intensity focused ultrasound for the treatment of adenomyosis: selection criteria, efficacy, safety and fertility. Acta Obstet Gynecol Scand 96(6):707-714 